3-Precision molding and casting processes

4-chemically bonded self-setting sand molding

5-Innovative molding and casting processes.

The casting process is ideal because it allows the formation of streamlined, intricate, integral parts of strength and rigidity obtainable by no other method of fabrication. The die-shape and size of the cavity of die are essential considerations in design; the possibilities of metal castings are unsurpassed.

In this experimental research, were used three types of metal casting to produce a spur gear made of aluminum alloy. These casting processes are pressure die casting centrifugal casting in different speeds and combining both methods.

\section{Selection of Casting Alloys}

The major factors that influence alloy selection for metal casting applications casting design, required properties, economic considerations and availability.

For these reasons aluminum alloy332.0-T5 has been chosen. It has good combination of foundry, mechanical, and physical characteristics, including low thermal expansion.

The two main Mechanical Tests that will work on it after casting Aluminum alloy to a spur gear are following:

1-Hardness Test (Vickers method)

2_Abrasive Wear Test

Y. Kuriyama, K. Yano and S. Nishido [2] illustrated that, pouring velocity for aluminum gravity casting the analysis technique that enables a reduction in time in fluid analysis simulations was proposed and pouring control input was optimized with the purpose of reducing occurrence of defects such as blow holes and pin holes in aluminum gravity casting.

Aakanksha Suryawanshi and Chandra.H [3] checked how to improve the quality of centrifugal casting by grey fuzzy method, by reducing defects in centrifugal casting for this problem randomly designs of eight experiments used to study the influence of process parameters on centrifugal casting of aluminum alloy.

P. Shailesh, B. Praveen Kumar, S. Sundarrajan and M. Komariahia [4] investigated experimental on centrifugal casting of 5500 aluminum alloy using Taguchi approach. A detailed investigation was carried on the selection of optimum mechanical properties of 5500 aluminum alloy by centrifugal casting using Taguchi method.

Kulkarni Sanjay Kumar, J K Sawale and Sampath Rao [5] studied the effect of process parameter setting on porosity levels of aluminum alloy SAE 308 by using Taguchi method.

Hans Ivar Laukli [6] studied the high pressure die casting of aluminium and magnesium alloys, grain structure and segregation characteristics.

Lubos Pavlak [7] investigated the effects of filling conditions on the quality of cast aluminum casting cylinder heads, showing that the filling conditions play a significant role on the casting quality.

Bellisario Denise, et.el [8] studied squeeze casting of Al-Si alloys. For studying squeeze casting, it is very substantial to evaluate the effectiveness of the pressure direct and indirect effects.

Guoding Yuan, et.el [9] researched the technology of aluminum alloy while low-pressure casting. In low-pressure casting, accurate control of technology, temperature, speed, and pressure parameters is necessary to achieve the stable and reliable quality assurance

\section{EXPERIMENTAL}

The machine was designed for producing the three different ways of pouring metal alloys inside metal die.

A table of machine was designed to carry the different parts of the machine like the die with its parts, the motor and the injection parts. Many considerations were taken into account; weight and stability on the ground which will bear the high performance and the rotation of the die. As shown in figure (1 and 2).

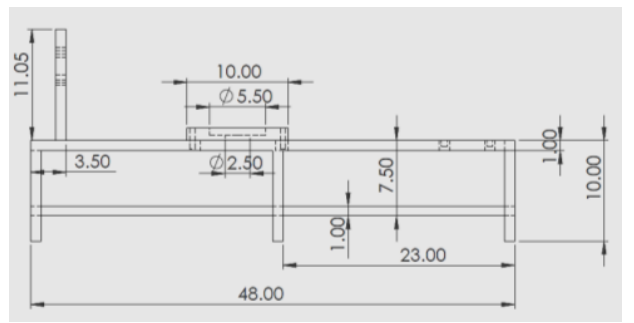

Figure .1 side view of table of machine

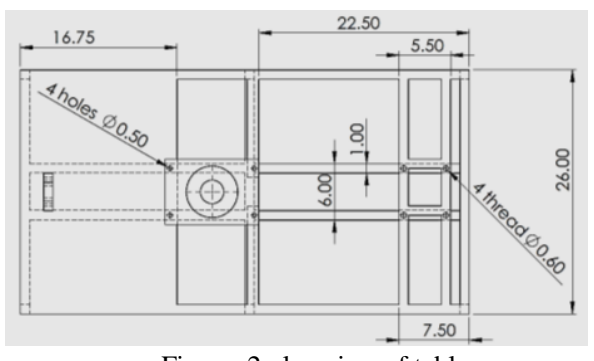

Figure .2 plan view of table

The die of the machine is a metal shaft form with diameter of $185 \mathrm{~mm}$ and is carried on a base and there is a pulley under the die's base attached to the die. Figure .3 shows the design of the die. This die has a cover with the same diameter while the thickness of $30 \mathrm{~mm}$ to resist the high temperature of molten aluminum alloy with a hole with $20 \mathrm{~mm}$ for pouring metal. As shown in figure (3).

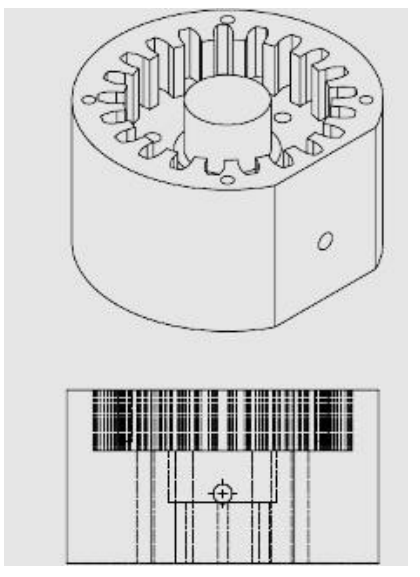

Figure .3 the design of die 
In Pressure Die Casting operation, it's necessary to design an injection method to help inject molten metal to the cavity of the die. So, a cylinder shaft with outer diameter of $130 \mathrm{~mm}$ and the inner is $100 \mathrm{~mm}$ was designed. Also there is a hole in side of the shaft for pouring molten metal. As shown in figure (4)

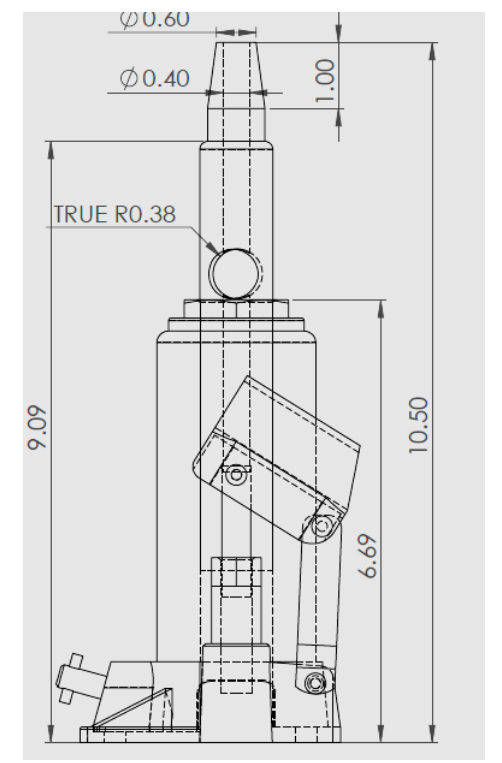

Figure .4 hydraulic jack

For centrifugal casting the same parts of machine were used in addition to a motor with suitable speed and revolution power for this process and centrifugal with pressure cast. The motor of 3 horse power and 1400 r.p.m was used, reducing the speed to 28 r.p.m and 50 r.p.m by a speed converter.

The die is a metal alloy chosen with consideration of the economical aspect, mechanical and physical characteristics .The commercial name of this metal alloy is 070M55or Carbon Steel EN 9.

Row alloy Carbon Steel En9 as a rod with diameter $185 \mathrm{~mm}$ and height $230 \mathrm{~mm}$ was bought. Rod prepared for machining on CNC milling machine.

After preparing the die and finishing machining the cavity die, a mill was made by the side of the die for pressure casting method to insure injection from this side Figure (5).

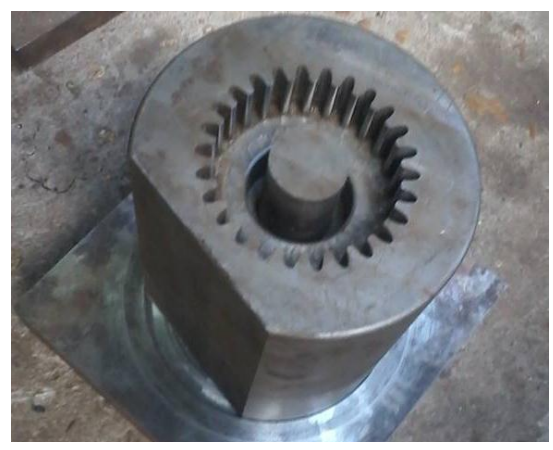

Figure.5 The die after milling

The die was prepared for drilling different holes inside cavity for the ejectors as shown figure (6).

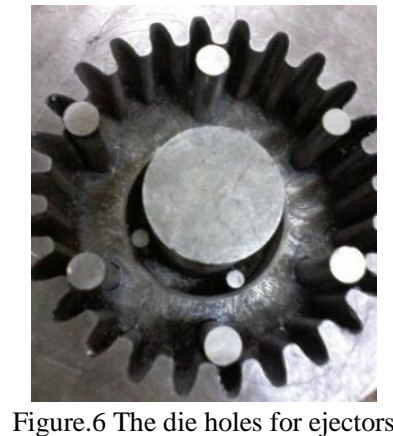

After finishing all the machining processes in dies and prepare it for the forming machine designed before, a hole was made

Machining in the side milled before for pressure casting.

The other parts will be fixed by screw bolts with die. These parts are base of die rod which will be fixed on base of die from downside and the bearing holder for all previous parts. With bearing and the cover of die cavity. Figure (7and8)

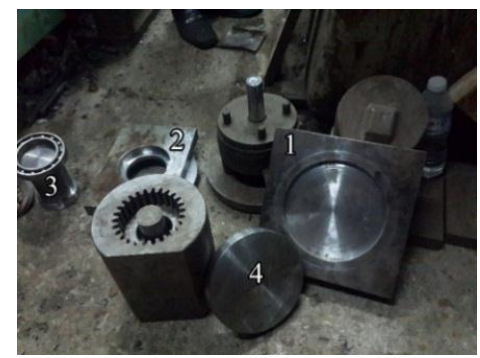

Figure.7 The die parts 1_base of die2_bearing holder 3_rod 4_Cover of Die

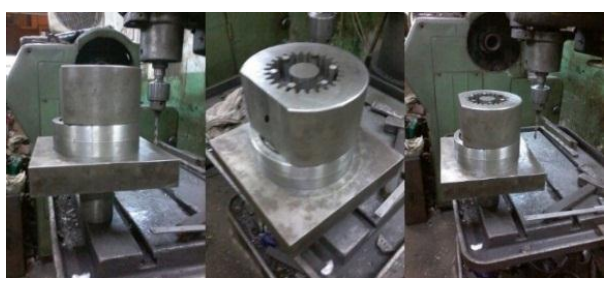

Figure. 8 the die parts fixed on table

For pressure casting, it needs a hole shaft which will be an outer body of inject and fixing a nozzle at the end of it and the other end will fixed with hydraulic screw which is fixed on a vertical metal plate. This metal plate is fixed with a carriage moved by screw jack prepared previously to make all parts which will be used in pressure method forwards and backwards the die Figure (9).

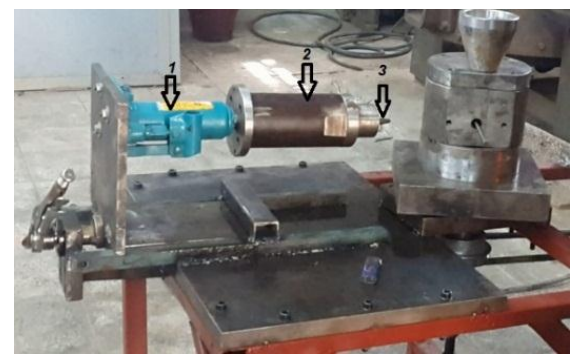

Figure.9 Machine parts 1- hydraulic jack, body of injection, 3-nozzel
2 -outer 
Before starting experiments, the oven should be prepared for melting of aluminum alloys.. The temperature of oven is about $750^{\circ} \mathrm{C}$. Also preparing die by use graphite and rub inside the cavity of the die and heating die to $300^{\circ} \mathrm{C}$ to facilitate injecting the samples after pouring

\section{Pouring to die}

The first method is centrifugal cast at Zero speed or by other words free pouring molten metal inside die's cavity without any external forces and making two samples of gears similar to die's cavity. As shown in figure(9).

\section{Centrifugal cast at 28 and 50 r.p.m}

The second method of casting is centrifugal casting at 28 r.p.m and 50 r.p.m, and pouring molten aluminum alloy while revolving die. At the end two samples of each speed are produced for being used in different mechanical tests that will explained later

\section{Pressure casting}

Molten aluminum alloy will be poured inside shaft injection and inject molten alloy with load 3 ton (hydraulic jack) towards cavity of the die.

$$
\begin{aligned}
& \mathrm{P}=\mathrm{F} / \mathrm{A} \\
& \mathrm{P}=3^{*} 1000 /\left[(\pi / 4) 7^{\wedge} 2\right]=77.465 \mathrm{~kg} / \mathrm{cm}^{\wedge} 2
\end{aligned}
$$

\section{Centrifugal casting with pressure casting}

In this process, centrifugal casting and pressure casting will be combined at the same time and producing samples. This process occurred by injecting molten metal towards cavity and revolving the die after the injection and producing two samples by injecting and rotating speed with 50 r.p.m.

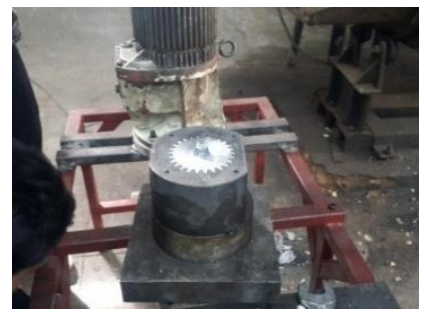

Figure. 10 casting process

The sample produce from all processes shown in figure (11).

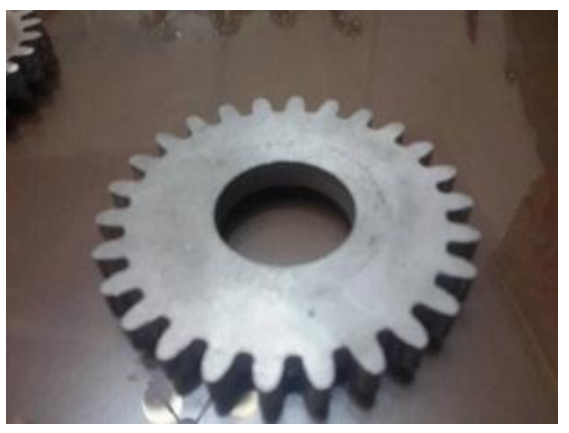

Figure.11 gear sample

\section{Mechanical Tests}

\section{Wear test}

This test was carried out at Gear Laboratory at The Faculty of Engineering - Mansoura University. This test was done by using a measuring wear machine. This machine consists of two separated parallelogram. Each one has a shaft on which the gears will be fixed. The lower one is attached with a pulley which connected to a motor by belt .There are a two springs fixed as shown in figure (12). These springs are calibrated to show the amount of load exert on gears during the experiment.

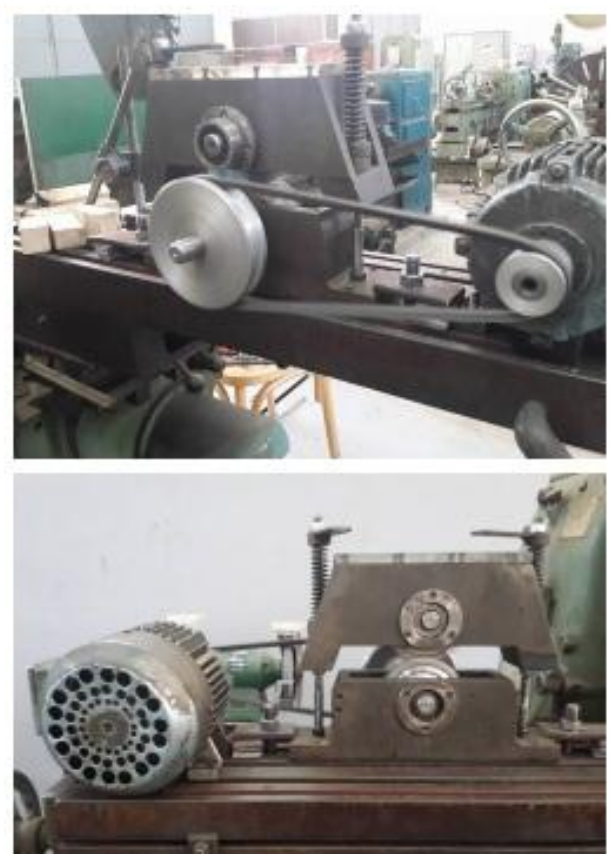

Figure 12. Wear testing machine

The test was done on different loads and speeds by changing the pulley diameter to $150 \mathrm{~mm}$ and $250 \mathrm{~mm}$ (motors' pulley is $50 \mathrm{~mm}$ ) with constant period of time.

Each two samples of the same die casting processes were tested together with changing loads every $15 \mathrm{~min}$ and measuring wear rate by sensible weight gauge shown in table

TABLE .1

LOAD EXERTED WITH SPEED

\begin{tabular}{|l|l|}
\hline load & speed \\
\hline $5 \mathrm{~kg}$ & 270 \\
\hline $10 \mathrm{~kg}$ & 270 \\
\hline $5 \mathrm{~kg}$ & 480 \\
\hline $10 \mathrm{~kg}$ & 480 \\
\hline
\end{tabular}

\section{Hardness test}

The test was done at Militarily Factory 63 in Helwan City. Measuring hardness is to observe the material's ability to resist plastic deformation from a standard source. The Vickers hardness test method consists of indenting the test material (Gear samples of die casting) with a diamond indenter, in the 
form of a right pyramid with a square base and an angle of 136 degrees with load $10 \mathrm{~kg}$. The full load is normally applied for 10 to 15 seconds. The two diagonals of the indentation left in the surface of the material after removing the load are measured using a microscope and their average is calculated. The area of the sloping surface of the indentation is calculated. The Vickers hardness is the quotient obtained by dividing the $\mathrm{kg}$ load by the square mm area of indentation Figure .13.

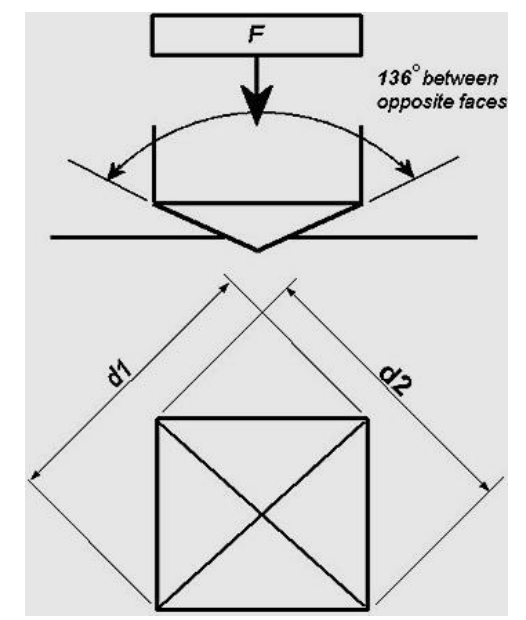

Figure.13.show Vickers hardiness test method

\section{RESUlts}

\section{Wear Test}

Wear rate according to load $5 \mathrm{~kg}$ for both speeds (480r.p.m for $15 \mathrm{~min}) .7200 \mathrm{rev}$ and (280r.p.m for $15 \mathrm{~min}$.) $4200 \mathrm{rev}$ for all tests, shown on diagram.1.

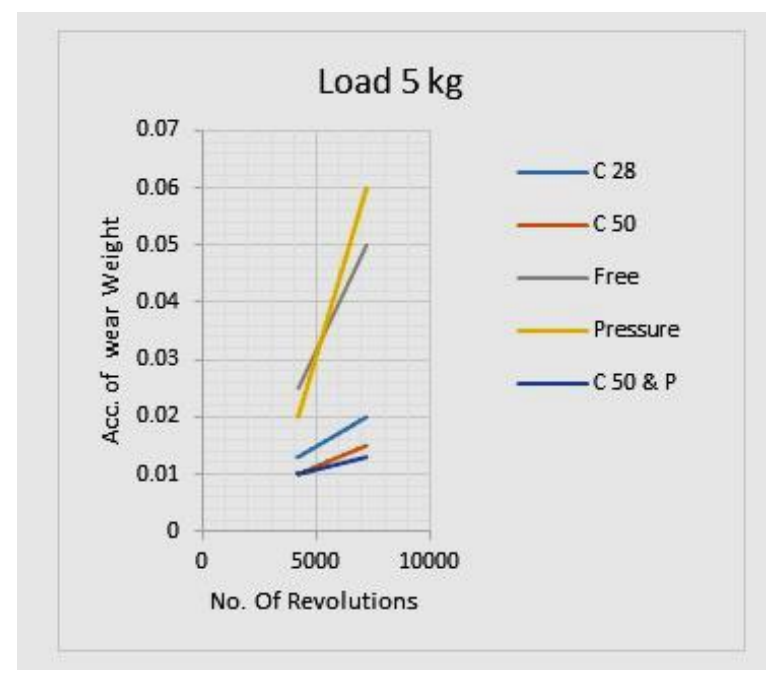

Diagram.1 wear rate with load $5 \mathrm{Kg}$

Also wear rate according to load $10 \mathrm{~kg}$ for both speeds (480r.p.m for $15 \mathrm{~min}) .7200 \mathrm{rev}$ and (280r.p.m for $15 \mathrm{~min}$.) 2400 rev for all tests, shown on diagram.2.

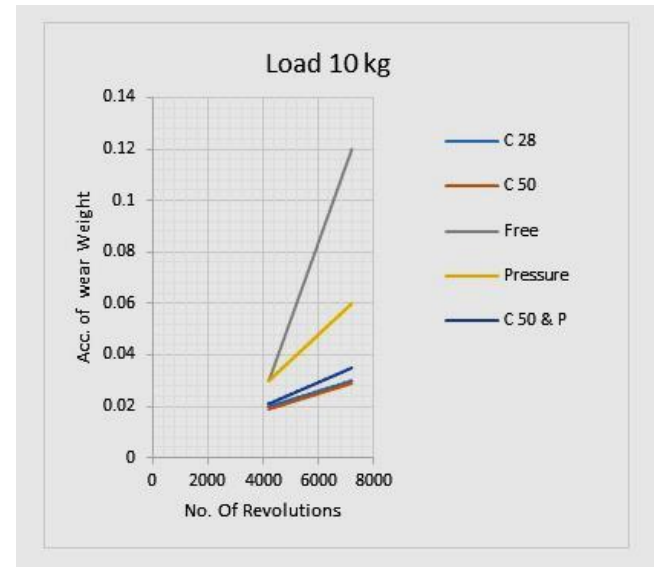

Diagram.2 wear rate with load $10 \mathrm{Kg}$

\section{Hardness Test}

- The result in samples of centrifugal casting with speed 50 r.p.m, on different teeth is 122 Vickers and this proves good distribution of the molten metal while casting process.Becouse the grain size is small at 50 r.p.m than other speed.

- For the sample of centrifugal casting with speed 28 r.p.m, the results on four different teeth on gear samples are 100.3, 100.3, 105.1, 105.1Vickers, so the measurement for the whole sample is 102.7 Vickers.

- Also the sample of centrifugal casting with speed zero r.p.m, the results on four different teeth on gear samples are $122,116,122,116$ Vickers, therefore the final result of this sample is 119 Vickers.

- For the sample of pressure casting with pressure force 3 tons, the results on four different teeth on gear samples are $122,122.3,116,116.1$ Vickers, so the measurement for the whole sample is 119.075 Vickers.

- For the sample of pressure casting with centrifugal casting with speed 50 r.p.m, the results on four different teeth on gear samples are 117, 116, 118, 122.1Vickers, so the measurement for the whole sample is 118.25 Vickers.

So the best hardness result for all previous tests is 122 Vickers for centrifugal casting process with speed 50 r.p.m.

\section{CONClusion}

According to all previous mechanical tests on all samples, it was concluded that:

1. The highest wear resistance with law wear rate sample according to wear test for all samples at high load is the sample which was produced from centrifugal casting with 50 r.p.m.

2. The best wear resist with law wear rate sample according to wear test for all samples at low load is the sample which was produced from pressure with centrifugal casting with 50 r.p.m.

3. The best hardness sample of all samples produced from different casting processes discussed before, is that the sample which was produced from centrifugal casting with 
50 r.p.m and is equal to 122 Vickers, because of the well distribution of molten aluminum alloys in all directions of die cavity.

4. It's also noticed that in centrifugal casting, the more speed increases; the better distribution of molten metal inside the cavity of die is achieved with good mechanical characteristics.

5. Also it's noticed that the sample from pressure casting is similar to the sample of pressure with centrifugal casting 50 r.p.m. That because centrifugal casting looks like indirect pressure obtained during revolving the die while casting process. That's why the molten sample was affected by pressure casting not centrifugal casting.

6. The most important notice is that the most affected sides while the gear is running or working are the top surface and the edge surface. That means the best samples are those which are produced from pressure casting and pressure with centrifugal casting 50 r.p.m.

\section{REFERENCES}

[1] -ASM Metals Handbook Collections

[2] -Y. Kuriyama, K. Yano and S. Nishido / Optimization of Pouring Velocity for Aluminium Gravity Casting, AISIN TAKAOKA CO, LTD,Japan,(2010).

[3] Aakanksha Suryawanshi1, Chandra.H, Shiena Shekhar / Optimization To Improve The Quality Of Centrifugal Casting By Grey Fuzzy Method,Int.journal of advanced eng,(2015).

[4] P. Shailesh*, B. Praveen Kumar, S. Sundarrajan and M. Komariahia / Experimental investigation on centrifugal casting of 5500 alloy: A Taguchi approach, scientific research and essays vol.7 (44)2012.

[5] Kulkarni Sanjay Kumar, J K Sawale, Sampath Rao / Study of effect of process parametersetting on porosity levels of aluminium pressure die casting process using Taguchi Methodology,IOSR journal of mechanical and civil eng.vol.9,(2013).

[6] Hans Ivar Laukli / High Pressure Die Casting of Aluminium and Magnesium Alloys -Grain Structure and Segregation Characteristics, Norwegian university of science and technology (2014) .

[7] Lubos Pavlak / Effect of Filling Conditions On The Quality Of Cast Aluminum CylinderHeads,Association of Metallurgical Engineers of Serbia AMES.

[8] Bellisario Denise, Boschetto Alberto, Costanza Girolamo, Tata Maria Elisa, QuadriniFabrizio and Santo Loredana / Squeeze Casting of Al-Si Alloys, Department of Mechanical Engineering, University of Roma, Italy.

[9] Guoding Yuan, Hai Gu ,Jianhua Sun, and Zhufeng LI / The Low-pressure CastingTechnology of aluminum alloy motor,3rd international conference on Material, Mechanical and Manufacturing Engineering (2015). 